\title{
Influência da prática musical em habilidades do processamento auditivo central: uma revisão sistemática
}

\author{
The influence of musical practice \\ in central auditory processing skills: \\ a systematic review
}

\section{Influencia de la práctica musical en habilidades del procesamiento auditivo central: una revisión sistemática}

\author{
Wilson Antunes Alves* \\ Talita Gallas dos Rei* \\ Cibele Cristina Boscolo* \\ Gabriele Donicht*
}

\section{Resumo}

Objetivo: Investigar o que a literatura revela sobre a influência da prática musical em habilidades do Processamento Auditivo Central (PAC), e se o tempo de exposição à música atua de alguma maneira nestas competências. Método: A coleta dos artigos foi realizada a partir das bases de dados PubMed, Science Direct e Lilacs, com a combinação de descritores indexados no Medical Subject Headings (MeSH). Critérios de seleção: Foram selecionados artigos em inglês e português, publicados entre os anos de 2010 e 2016, cujo título, ou resumo, ou corpo do trabalho, tivessem relação com o objetivo do presente estudo. Foram excluídos os artigos repetidos e os que não possuíam o resumo ou texto completo, artigos

* Centro Universitário Metodista - IPA, Porto Alegre, Rio Grande do Sul, Brasil

**Faculdade Nossa Senhora de Fátima, Caxias do Sul, Rio Grande do Sul, Brasil

Contribuição dos autores:

WAA - como autor principal,

foi responsável pela concepção do estudo, metodologia, coleta de dados, esboço do artigo e revisão crítica.

TGR - auxiliou na metodologia e revisão crítica.

CCB - realizou a revisão crítica e orientação.

GD - foi a principal orientadora e responsável pela concepção do estudo, metodologia, revisão crítica e orientação.

E-mail para correspondência: Wilson Antunes Alves wilsonantunesalves@gmail.com

Recebido: $19 / 12 / 2017$

Aprovado: 22/05/2018 
de revisão, dissertações e teses. Análise dos dados: Após a leitura dos artigos na íntegra, foram extraídos os seguintes dados: título, ano de publicação, país de origem, idade e características dos indivíduos da amostra, tipo de estudo, tempo de experiência dos músicos, objetivo da pesquisa, habilidades do PAC avaliadas, resultados encontrados e conclusão. Resultados: A pesquisa realizada gerou o total de 1445 artigos, sendo que 896 deles estavam contidos na Pubmed, 518 na base ScienceDirect e 31 na Lilacs. Ao final da análise, os juízes selecionaram 17 estudos. Conclusão: Os artigos mencionados demonstraram que a prática musical influencia positivamente as habilidades do PAC, não havendo um consenso quanto à atuação do tempo de exposição sobre essas competências, mas evidenciando um melhor resultado de indivíduos com maior experiência musical.

Palavras-chave: Música; Percepção Auditiva; Revisão; Testes Auditivos; Córtex Auditivo.

\section{Abstract}

Objective: To investigate what the literature reveals about the influence of the musical practice on Central Auditory Processing (CAP) skills, and whether the time of exposure to music acts in some way in these skills. Method: The collection of the articles was carried out from the databases PubMed, Science Direct and Lilacs, with the combination of indexed descriptors in the Medical Subject Headings (MeSH). Selection criteria: Articles were selected in English and Portuguese, published between 2010 and 2016, whose title, or abstract, or work content, were related to the objective of the present study, that is to verify the influence of music in the CAP. The repeated articles and those that did not have the abstract or full text, revision articles, dissertations and theses were excluded. Data analysis: After reading the articles in full, the data were extracted: title, year of publication, country of origin, age and characteristics of the examples, type of study, musicians' experience time, research objective, CAP skills assessed, results found and conclusion. Results: The research carried out generated a total of 1445 articles, 896 of them were contained in Pubmed, 518 in the base ScienceDirect and 31 in Lilacs. At the end of the analysis the judges selected 17 studies. Conclusion: The articles mentioned demonstrate that the musical practice positively influences the abilities of the CAP. There was no consensus regarding the performance of the exposure time on these skills, but it was shown a better result for individuals with greater musical experience.

Keywords: Music; Auditory Perception; Review; Hearing Tests; Auditory Cortex.

\section{Resumen}

Objetivo: Investigar lo que la literatura revela sobre la influencia de la práctica musical en habilidades del Procesamiento Auditivo Central (PAC), y si el tiempo de exposición a la música actúa de alguna manera en estas competencias. Método: La recolección de los artículos se realizó a partir de las bases de datos PubMed, ScienceDirect y Lilacs, con la combinación de descriptores indexados en el Medical Subject Headings (MeSH). Criterios de selección: Se seleccionaron artículos en inglés y portugués, publicados entre los años de 2010 a 2016, cuyo título, resumen, cuerpo del trabajo, tuvieran relación con el objetivo del presente estudio. Se excluyeron los artículos repetidos, los que no poseían el resumen o texto completo, artículos de revisión, disertaciones y tesis. Análisis de los datos: Después de la lectura de los artículos en su totalidad, se extrajeron los siguientes datos: título, año de publicación, país de origen, edad y características de los individuos de la muestra, tipo de estudio, tiempo de experiencia de los músicos, objetivo de la investigación, habilidades del PAC evaluadas, resultados encontrados y conclusión. Resultados: La encuesta realizada generó el total de 1445 artículos, 896 de ellos estaban en la base Pubmed, 518 en ScienceDirect y 31 en Lilacs. Al final del análisis, los jueces seleccionaron 17 estudios. Conclusión: Los artículos mencionados demostraron que la práctica musical influye positivamente en las habilidades del PAC, no habiendo un consenso cuanto a la actuación del tiempo de exposición sobre esas competencias, pero evidenciando un mejor resultado de individuos con mayor experiencia musical.

Palabras clave: Música; Percepción Auditiva; Revisión; Pruebas Auditivas; Corteza Auditiva. 


\section{Introdução}

O processamento auditivo central (PAC) diz respeito a como os indivíduos analisam as informações acústicas que são recebidas via sentido da audição, atuando no desenvolvimento da linguagem e das habilidades acadêmicas e também do processo de comunicação ${ }^{1}$. Pode ser conceituado como um conjunto de habilidades específicas das quais o indivíduo depende para compreender o que ouve. É uma atividade mental, por isso, não pode ser estudada como um fenômeno distinto, mas sim como uma resposta complexa aos estímulos recebidos por meio da audição².

Em geral, o PAC pode ser definido como a habilidade de perceber os estímulos sonoros a nossa volta, analisando e memorizando aquilo que se ouve. Para isso, é necessário que as vias responsáveis pelo caminho do som, e pela sua interpretação, estejam íntegras. Quando existe alguma interferência nesse percurso estamos diante de um Transtorno do Processamento Auditivo Central (TPAC) $)^{3}$.

O TPAC refere-se a dificuldades no processamento perceptual da informação auditiva no Sistema Nervoso Central (SNC) e atividade neurobiológica que subjaz à transformação. Dificuldade de compreender a fala em um ambiente ruidoso, apesar de os limiares auditivos se mostrarem normais, é a marca da DPAC ${ }^{4}$. Além disso, faz com que ocorram dificuldades na interpretação dos padrões sonoros, prejudicando o indivíduo ao atender, discriminar, reconhecer, recordar e/ou compreender informações apresentadas aos canais auditivos ${ }^{5}$.

O processamento auditivo temporal (PAT) pode ser definido como a percepção do som ou a alteração do som dentro de um domínio de tempo restrito ou definido, ou seja, refere-se à habilidade de perceber ou diferenciar estímulos que são apresentados numa rápida sucessão ${ }^{6}$. As habilidades do PAT são extremamente necessárias para a capacidade de entender a fala no ruído e no silêncio, assim como estímulos de fala e outros sons de fundo que variam ao longo do tempo. Podem, também, ser consideradas a base para o processamento auditivo, já que muitas características das informações auditivas são influenciadas pelo tempo ${ }^{6}$.

A percepção das informações de tempo como duração, intervalo e ordem de diferentes padrões de estímulo fornece informações fundamentais para o sistema nervoso central. Estas pistas regem o processamento temporal e são importantes para a percepção da fala e da música, uma vez que a estrutura destes eventos apresenta-se como rápidas mudanças do sinal acústico ${ }^{6}$.

O PAT é dividido em quatro categorias, sendo todas importantes para as habilidades do PAC; são elas: ordenação ou sequencialização temporal, que se refere ao processamento de múltiplos estímulos auditivos na sua ordem de ocorrência; integração, que decorre da somação da atividade neuronal, resultante de uma adicional duração da energia sonora; em testes que avaliam a integração temporal, os sujeitos devem detectar sinais fracos em meio a um ruído de fundo ou no silêncio; mascaramento temporal, que ocorre quando um estímulo é apresentado com duração e intensidade suficientes para reduzir a sensibilidade de outro estímulo apresentado antes ou depois do estímulo inicial; resolução, discriminação ou acuidade temporal, a qual se refere ao mínimo de tempo requerido para segregar ou resolver eventos acústicos ${ }^{6,7,8}$.

Ao que tudo indica, é na área secundária direita cerebral que são processados os sons ambientais e musicais, e na esquerda os sons da fala. Dessa forma, o hemisfério esquerdo é dominante para a linguagem e fala, e para o reconhecimento e processamento de informações sequenciais. Já o hemisfério direito é dominante para reconhecer contornos, como a música9 .

O SNC processa a música diversamente de outros estímulos auditivos no córtex temporal em três áreas. A área auditiva primária é responsável pelo reconhecimento, analisando cada som isoladamente, mas de forma sequente no tempo. Já à área auditiva secundária cabe a integração dos sons individuais em grupos maiores onde são valorados novos significados, como ritmo, harmonia e melodia. A área auditiva terciária integra os grupos de notas musicais em temas maiores, hierarquizando, ponderando e organizando de forma temporal, até obter uma imagem completa, integral e diversa de toda a música ${ }^{10}$. Além destas, outras áreas cerebrais são ativadas para o processamento da informação musical, como áreas de memória tal como o hipocampo, que reconhece a familiaridade dos elementos temáticos e rítmicos; as áreas de regulação motora e emocional como o cerebelo e a amígdala, que atribuem um valor emocional à experiência sonora, e um núcleo de substância cinzenta (núcleo acumbens) relacionado ao sentido de prazer e recompensa ${ }^{11}$. 
Sendo assim, por meio da realização de uma revisão sistemática, o presente estudo tem como objetivo investigar o que a literatura revela sobre a influência da prática musical em habilidades do Processamento Auditivo Central, e se o tempo de exposição à música atua de alguma maneira nestas competências.

\section{Método}

\section{Estratégias de Pesquisa}

Para esta revisão sistemática, foram seguidos os preceitos do Cochrane handbook ${ }^{12}$, que envolvem a formulação da questão de pesquisa, a localização, a seleção dos artigos científicos e a avaliação crítica deles. Considerando que a revisão sistemática é realizada a partir da formulação de perguntas específicas que direcionam a busca das publicações envolvendo o tema, a questão investigativa do presente estudo foi: "Qual a influência que a prática musical exerce nas habilidades do processamento auditivo central?".

A pesquisa foi desenvolvida por três pesquisadores, sendo que um realizou a busca dos artigos de forma independente e cega, enquanto os outros dois foram instituídos como juízes, sendo consultados nos casos de dúvida para estabelecer uma concordância entre as ideias.

A coleta dos artigos foi realizada a partir das bases de dados PubMed, Science Direct e Lilacs. A busca foi realizada no mês de setembro, em um único dia, a partir do cruzamento entre os descritores eleitos. Como estratégia de busca foi utilizada a combinação de descritores indexados no Medical Subject Headings (MeSH). Foram utilizadas as seguintes palavras-chave: Auditory Perception or Auditory Threshold or Auditory Fatigue or Loudness Perception or Perceptual Masking or Pitch Perception or Pitch Discrimination or Sound Localization or Speech Perception and Music or Singing and Hearing Test or Test, Hearing or Tests, Hearing.

\section{Critérios de Seleção}

Foram selecionados artigos em inglês e português, publicados entre os anos de 2010 e 2016, realizados com seres humanos, cujo título, ou resumo, ou corpo do trabalho, tivessem relação com o objetivo do presente estudo, que foi verificar a influência da música no processamento auditivo central. Excluíram-se os artigos repetidos e os que não possuíam o resumo ou texto completo, artigos de revisão, dissertações e teses. Além dos trabalhos nos quais não fossem comparados indivíduos com experiência em prática musical dos indivíduos não músicos.

Todos os artigos encontrados passaram por análise de dois juízes, os quais preencheram um formulário de elegibilidade e, por meio dele, incluíram ou excluíram os estudos, de acordo com os critérios descritos. Aqueles que deixaram margens de dúvidas para elegibilidade foram lidos na íntegra. Um terceiro juiz realizou a análise da concordância entre os artigos, decidindo os casos em que houve discordância.

\section{Análise dos Dados}

Os artigos foram analisados qualitativamente, de acordo com os critérios de inclusão e com base na questão norteadora deste estudo. Já para análise dos dados quantitativos, realizou-se uma análise descritiva de frequência em números absolutos e percentuais.

A partir da seleção dos resumos dos estudos encontrados, pertinentes à questão proposta, foi realizada a recuperação dos artigos em texto completo. Após a leitura dos artigos na íntegra, foram extraídos os seguintes dados: título, ano de publicação, país de origem, idade e características dos indivíduos da amostra, tipo de estudo, tempo de experiência dos músicos, objetivo da pesquisa, habilidades do PAC avaliadas, resultados encontrados e conclusão. 


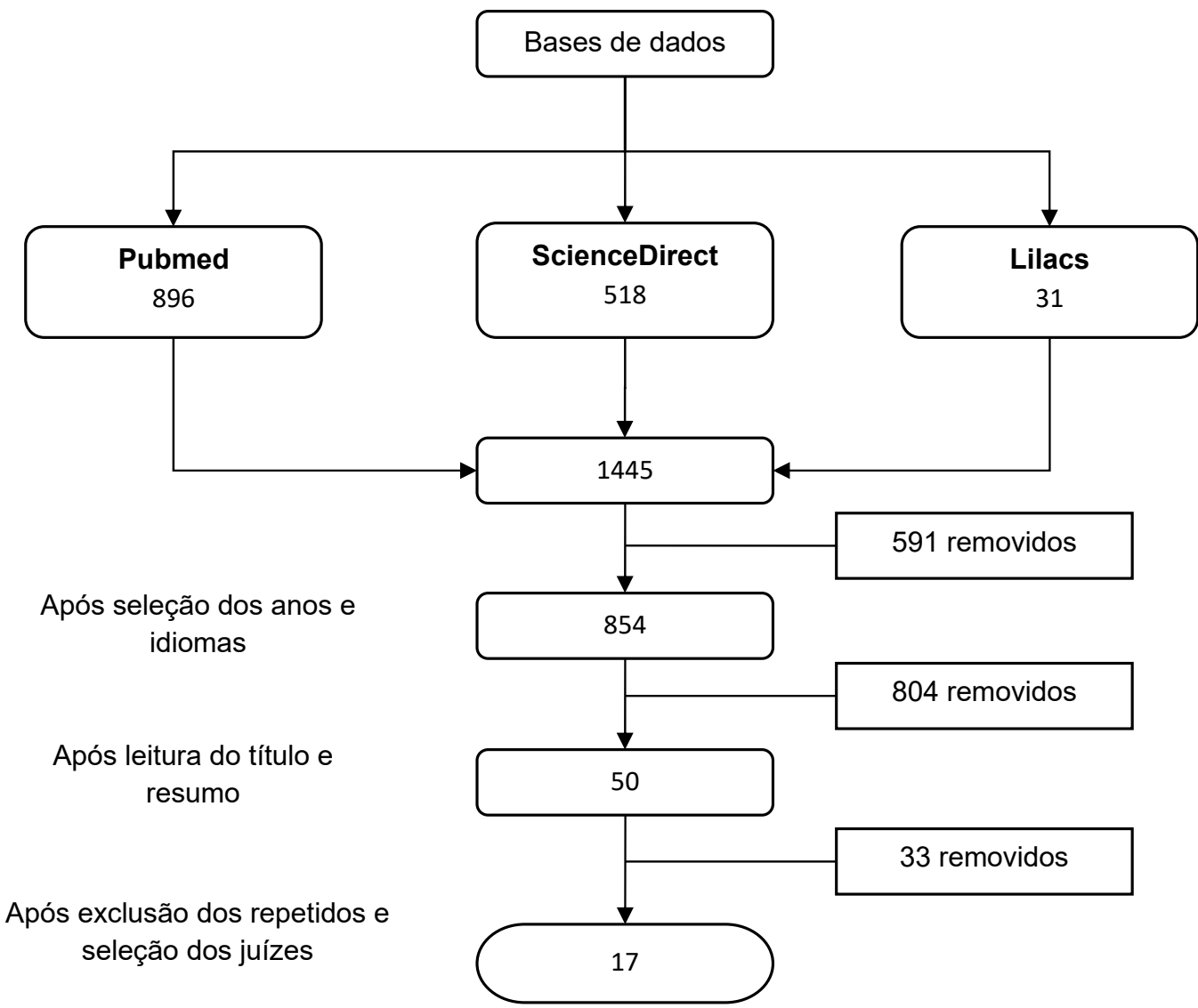

Figura 1. Número de artigos encontrados e selecionados após aplicação dos critérios de inclusão e exclusão segundo descritores e bases de dados.

\section{Resultados e discussão}

A pesquisa realizada nas bases de dados utilizadas, a partir dos descritores propostos, gerou o total de 1445 artigos. O quantitativo de referências encontradas e selecionadas nas bases de dados para este estudo mostra que $896(62,1 \%)$ delas estavam contidas na Pubmed, 518 (35,8\%) na base ScienceDirect e $31(2,1 \%)$ na base Lilacs. Após serem filtrados pelos idiomas selecionados, inglês e português, restaram 854 artigos, os quais, logo em seguida, passaram por análise dos títulos e resumos a partir dos critérios de inclusão e exclusão adotados. Destes, foram excluídos ainda 804, restando 50 artigos para a análise do texto completo. A partir da leitura destes e da exclusão daqueles que não se encaixavam nos critérios de inclusão, os juízes selecionaram 17 estudos para análise (Figura 1).
Nos artigos selecionados para o presente estudo foram extraídos os seguintes dados para análise: título, ano de publicação, país de origem, idade e características dos indivíduos da amostra, tipo de estudo, tempo de experiência dos músicos, objetivo da pesquisa, habilidades do PAC avaliadas, resultados encontrados e conclusão (Tabela 1).

As datas de publicação variaram entre os anos de 2010 e 2016, previamente selecionados por englobarem os trabalhos mais atuais. Do total, três publicações ocorreram no ano de $2010^{13,14,15}$; duas no ano de $2011^{16,17}$; seis no ano de $2012^{18,19,20,21,22,23}$; uma no ano de $2014^{24}$; quatro no ano de $2015^{25,26,27,28}$; e uma no ano de $2016^{29}$; no ano de 2013 não foram encontradas publicações que obedecessem aos critérios de inclusão propostos nesta pesquisa. Este demonstrativo leva a inferir que no período atual houve um aumento de publicações que tratam do tema deste estudo, visto que 
a área do Processamento Auditivo ganhou maior repercussão nos últimos anos. Este fato pode ter relação com o surgimento de novos estudos que relacionam essa área com a música.

Dos artigos publicados, seis foram desenvolvidos nos Estados Unidos da América (EUA) $)^{13,19,23,24,26,27}$; quatro no Brasi1 $1^{14,15,16,25}$; dois no Canadá18,22, Reino Unido ${ }^{28,29}$ e Itália ${ }^{20,21}$; e um em Israel ${ }^{17}$. Este resultado pode estar relacionado aos testes que avaliam o PAT terem sido criados e comercializados, em sua grande maioria, nos EUA. No Brasil, contamos também com os testes produzidos pelas Fonoaudiólogas Liliane Desgualdo Pereira e Eliane Schochat. O único estudo selecionado que não foi produzido no Ocidente, mas sim em um país que fica no Oriente Médio ${ }^{17}$, investigou os efeitos do contexto de estímulo e da experiência musical sobre a discriminação auditiva de intervalo temporal, concluiu que em músicos a habilidade de resolução temporal mostrou-se mais desenvolvida do que em indivíduos sem experiência musical.

No que se refere aos sujeitos da pesquisa, as amostras foram bastante variadas e envolveram crianças, adultos e idosos. O tamanho da amostra variou entre 21 e 163 participantes. $\mathrm{O}$ artigo contendo a amostra com 163 participantes foi desenvolvido com uma população bastante heterogênea, com indivíduos de ambos os sexos, entre 18 e 91 anos de idade, e características diversas ${ }^{22}$.

Em relação à faixa etária dos estudos, 15 investigaram indivíduos adultos, sendo que 11 informaram a média de idade dos participantes ${ }^{13,17,18,20,21,23,24,25,26,28,29} \mathrm{e}$ em quatro não consta esta informação ${ }^{14,15,19,22}$. A média de idade da amostra ficou em 25,2 anos. Apenas dois estudos foram realizados com crianças em idade escolar; em um deles a média de idade foi de $5,5 \operatorname{anos}^{16}$ e no outro 8 anos $^{27}$.

Quanto ao delineamento dos estudos, verificou-se que a maioria apresentou delineamento transversal $1^{14,15,16,17,18,19,20,21,23,24,25,26,28}$, e consistiram basicamente na comparação entre dois grupos, um composto por músicos e outro por indivíduos não músicos, na realização de testes que avaliavam habilidades do PAC. O maior nível de evidência científica encontrado nos estudos selecionados foi o estudo de coorte ${ }^{13,22,27}$, presente em apenas três artigos, todos internacionais. Em relação ao método utilizado nos artigos incluídos no presente estudo, destacam-se dois que utilizaram grupos específicos de músicos violinistas na realização de testes que avaliam as habilidades de ordenação temporal e resolução temporal ${ }^{13,14}$. Nos demais estudos, não houve uma especificação quanto ao instrumento praticado pelos músicos.

Sobre o tempo mínimo de prática musical exigido aos participantes músicos nos estudos selecionados, o menor período foi de apenas quatro meses ${ }^{16}$ e o maior ficou com a média de 12 anos $^{20}$, sendo que neste mesmo estudo havia indivíduos com experiência musical muito maior do que a exigida. A média geral dos estudos foi 7,6 anos de envolvimento prático com a música, seja por tocar algum instrumento ou cantar. A literatura defende que, para se atingir altos níveis de desempenho, são necessários, pelo menos, dez anos de prática ordenada no domínio do instrumento escolhido; também afirmam que atividades relacionadas à prática informal, como participar de atividades musicais exploratórias e prazerosas, encorajam o desenvolvimento da expressividade musical e contribuem para a formação do músico, ainda que em menor grau que a prática de escalas e de repertório ${ }^{30}$.

Todos os estudos utilizaram músicos com experiência prévia ao experimento no grupo estudo, com exceção de apenas dois ${ }^{16,27} \mathrm{em}$ que os indivíduos não tiveram treinamento musical em um período anterior ao do estudo. No primeiro deles ${ }^{16}$, o objetivo consistiu em investigar as relações entre experiência musical, habilidades de processamento auditivo e de consciência fonológica de crianças de 5 anos de idade, em que o grupo 1 passou a participar de aulas de musicalização infantil por pelo menos uma hora por semana, durante, pelo menos, quatro meses, e concluiu-se que o grupo que passou por esse treinamento obteve melhores resultados se comparado com o grupo que não passou por essa experiência, nos resultados das habilidade de ordenação temporal. No segundo estudo $^{27}$, realizado com crianças que tinham a média de idade de oito anos, e que teve como objetivo realizar uma investigação do efeito da instrução de música em grupo sobre o desempenho em uma medida de percepção de fala em ruído, a população com maior tempo de treinamento musical obteve os melhores resultados nos testes realizados que avaliam a habilidade de figura-fundo, concluindo que tal treinamento provoca efeitos benéficos sobre esta competência.

Nos artigos selecionados foram avaliadas e testadas quatro competências presentes no PAC, 
sendo a maior parte delas correspondentes ao PAT. Esse dado revela uma maior tendência por parte dos pesquisadores em correlacionar tais habilidades com a prática musical, levando em consideração que a música utiliza formas distintas de duração, intervalo e sequência de diferentes padrões de estímulo, importantes para a percepção da fala e da música, uma vez que a estrutura destes dois eventos apresenta-se como rápidas mudanças de sinais acústicos ${ }^{14}$. A investigação da habilidade de resolução temporal foi a mais abordada, correspondendo a sete estudos ${ }^{15,17,19,20,22,24,25}$; em cinco foi avaliada a habilidade de figura-fundo $22,23,26,27,28$; em quatro, a ordenação temporal ${ }^{14,16,21,25}$; e, em três artigos, os testes envolveram a habilidade de discriminação auditiva ${ }^{13,18,29}$.

Observou-se um uso de uma gama variada de testes para a realização das avaliações. Destacam-se o uso do Gap in Noise (GIN), para a avaliação da habilidade de resolução temporal ${ }^{15,25}$; o Teste de Padrão de Frequência (TPF), para avaliação da ordenação temporal ${ }^{14,25}$; o uso de melodias que terminavam em uma nota esperada ou inesperada emparelhado com enunciados prosódicos para a avaliação da discriminação auditiva ${ }^{29}$; e medidas de percepção de fala no ruído, para avaliação da habilidade de figura fundo ${ }^{26,27,28}$.

Em todos os estudos a hipótese testada foi a de que a experiência musical traria vantagens sobre as habilidades do processamento do som pelo cérebro, em relação aos indivíduos com nenhum ou restrito contato prático com a música. Os resultados encontrados na maior parte dos artigos trouxeram como desfecho o que era esperado: a música contribui positivamente sobre essas competências. Porém, na pesquisa realizada com músicos violinistas, não houve diferença nos resultados do teste GIN, quanto ao desempenho, e nem no tempo de exposição diária à música ${ }^{15}$. Já no experimento realizado entre cantores populares que tocam ou não instrumentos, o mesmo teste revelou que cantores populares que tocam instrumentos musicais apresentam melhor desempenho em habilidades auditivas quando comparados àqueles que só cantam ${ }^{25}$. No estudo que objetivou estimar se, e de que maneira, os músicos experientes diferem dos não músicos em sua percepção da fala mascarada, não foi encontrada nenhuma vantagem para a percepção de fala mascarada dos músicos sobre a de não músicos, e isso não variou quanto ao de tipo ruído ${ }^{28}$.

O presente estudo buscou verificar se a influência da prática musical e o tempo de exposição à música atuam nas habilidades do PAC; contudo, acredita-se que novos estudos sejam necessários para que se possam considerar outros pontos importantes, como as diferenças entre pessoas que se dedicaram ao estudo de instrumentos fundamentalmente melódicos, e as que se dedicaram a instrumentos essencialmente percussivos e rítmicos, sabendo-se da diferença da dominância cerebral para habilidades auditivas específicas (percepção melódica, harmônica e rítmica). Também valeria considerar estudos com grupo de crianças com exposição e experiências musicais durante a primeira infância, período fundamental para o desenvolvimento de habilidades auditivas, seja para a aquisição e desenvolvimento da linguagem, como para o desenvolvimento de habilidades musicais. 
Tabela 1. Resultados dos estudos selecionados seguindo as variáveis analisadas

\begin{tabular}{|c|c|c|c|c|c|}
\hline $\begin{array}{l}\text { Autor(es), } \\
\text { ano e país }\end{array}$ & Amostra & $\begin{array}{l}\text { Tipo de } \\
\text { estudo }\end{array}$ & $\begin{array}{c}\text { Habilidade(s) } \\
\text { testada(s) }\end{array}$ & Objetivo & Resultados e conclusão \\
\hline $\begin{array}{l}\text { Wayland et } \\
\text { al. (2010) } \\
\text { (13) Estados } \\
\text { Unidos da } \\
\text { América }\end{array}$ & $\begin{array}{c}\text { Grupo 1: } 15 \\
\text { músicos c/ no } \\
\text { mínimo } 6 \text { anos de } \\
\text { experiência } \\
\text { Grupo 2: } 15 \text { não } \\
\text { músicos } \\
\text { Média de idade: } \\
\text { 22,5 anos. }\end{array}$ & Coorte & $\begin{array}{l}\text { Discriminação } \\
\text { auditiva }\end{array}$ & $\begin{array}{l}\text { Examinar os efei- } \\
\text { tos da experiên- } \\
\text { cia e treinamento } \\
\text { musical sobre a } \\
\text { percepção do con- } \\
\text { torno tonal. }\end{array}$ & $\begin{array}{l}\text { Os resultados sugerem que a } \\
\text { experiência musical agudizou } \\
\text { a percepção de afinação en- } \\
\text { tre os músicos, mas que os } \\
\text { sistemas auditivos de ambos } \\
\text { os grupos são dependentes } \\
\text { da experiência e comparati- } \\
\text { vamente maleáveis. }\end{array}$ \\
\hline $\begin{array}{l}\text { Nascimento } \\
\text { et al. (2010) } \\
\text { (14) Brasil }\end{array}$ & $\begin{array}{c}\text { Grupo 1: } 20 \\
\text { músicos todos } \\
\text { com formação } \\
\text { musical } \\
\text { Grupo 2: } 20 \text { não } \\
\text { músicos } \\
\text { Média de idade: } \\
\text { não informada }\end{array}$ & Transversal & $\begin{array}{l}\text { Ordenação } \\
\text { temporal }\end{array}$ & $\begin{array}{l}\text { Comparar a habi- } \\
\text { lidade de ordena- } \\
\text { ção entre músicos } \\
\text { e não músicos a } \\
\text { partir do teste de } \\
\text { padrão de frequ- } \\
\text { ência. }\end{array}$ & $\begin{array}{l}\text { Os resultados do Teste de } \\
\text { Padrão de Frequência (TPF) } \\
\text { foram correlacionados com a } \\
\text { média das frequências graves, } \\
\text { média tritonal e média das } \\
\text { frequências agudas obtendo } \\
\text { relação estatisticamente sig- } \\
\text { nificativa apenas para OD. } \\
\text { O desempenho do grupo de } \\
\text { músicos no TPF foi superior } \\
\text { ao grupo de não músicos. } \\
\text { Destaca-se a relevância dos } \\
\text { limiares auditivos para as } \\
\text { frequências graves, agudas e } \\
\text { média tritonal no desempenho } \\
\text { do TPF na orelha direita. }\end{array}$ \\
\hline $\begin{array}{l}\text { Monteiro et } \\
\text { al. }(2010)^{(15)} \\
\text { Brasil }\end{array}$ & $\begin{array}{c}\text { Grupo 1: } 20 \\
\text { músicos todos } \\
\text { com formação } \\
\text { musical } \\
\text { Grupo 2: } 20 \text { não } \\
\text { músicos } \\
\text { Média de idade: } \\
\text { não informada }\end{array}$ & Transversal & $\begin{array}{l}\text { Resolução } \\
\text { temporal }\end{array}$ & $\begin{array}{l}\text { Identificar o de- } \\
\text { sempenho da re- } \\
\text { solução temporal } \\
\text { entre os grupos e } \\
\text { correlacioná-lo à } \\
\text { média dos limiares } \\
\text { das frequências } \\
\text { graves e agudas, } \\
\text { bem como, ao } \\
\text { tempo de exposi- } \\
\text { ção diária à mú- } \\
\text { sica. }\end{array}$ & $\begin{array}{l}\text { A média das frequências gra- } \\
\text { ves para ambas as orelhas no } \\
\text { grupo de músicos foi estatis- } \\
\text { ticamente significativa sendo } \\
\text { os maiores valores para OD } \\
(\mathrm{p}=0,001) \text {. Não houve dife- } \\
\text { rença entre o desempenho do } \\
\text { teste Gap in Noise (GIN) para } \\
\text { ambos os grupos assim como } \\
\text { a correlação entre o tempo de } \\
\text { exposição diária a música e o } \\
\text { GIN. O limiar audiométrico das } \\
\text { frequências agudas mostrou- } \\
\text {-se relevante na realização do } \\
\text { teste GIN. }\end{array}$ \\
\hline $\begin{array}{l}\text { Escalda et } \\
\text { al. }(2011)^{(16)} \\
\text { Brasil }\end{array}$ & $\begin{array}{c}\text { Grupo 1: } 30 \\
\text { com } 4 \text { meses } \\
\text { de experiência } \\
\text { musical } \\
\text { Grupo 2: } 26 \\
\text { sem experiência } \\
\text { musical } \\
\text { Média de idade: } \\
\text { 5,5 anos }\end{array}$ & Transversal & $\begin{array}{c}\text { Ordenação } \\
\text { temporal }\end{array}$ & $\begin{array}{l}\text { Investigar as re- } \\
\text { lações entre ex- } \\
\text { periência musi- } \\
\text { cal, habilidades } \\
\text { de processamen- } \\
\text { to auditivo e de } \\
\text { consciência fono- } \\
\text { lógica de crianças } \\
\text { de } 5 \text { anos de idade } \\
\text { com e sem experi- } \\
\text { ência musical. }\end{array}$ & $\begin{array}{l}\text { Observou-se diferença entre } \\
\text { os resultados obtidos nos } \\
\text { testes de memória sequencial } \\
\text { verbal e memória sequencial } \\
\text { não verbal com quatro ins- } \\
\text { trumentos, tarefas de iden- } \\
\text { tificação de rimas, síntese e } \\
\text { exclusão fonêmica. A expe- } \\
\text { riência musical promove o } \\
\text { aprimoramento de habilidades } \\
\text { auditivas e metalinguísticas de } \\
\text { crianças de } 5 \text { anos. }\end{array}$ \\
\hline
\end{tabular}




\begin{tabular}{|c|c|c|c|c|c|}
\hline $\begin{array}{l}\text { Autor(es), } \\
\text { ano e país }\end{array}$ & Amostra & $\begin{array}{l}\text { Tipo de } \\
\text { estudo }\end{array}$ & $\begin{array}{c}\text { Habilidade(s) } \\
\text { testada(s) }\end{array}$ & Objetivo & Resultados e conclusão \\
\hline $\begin{array}{c}\text { Banai et al. } \\
(2011)^{(17)} \\
\text { Israel }\end{array}$ & $\begin{array}{c}\text { Grupo 1: } 24 \\
\text { músicos c/ } \\
\text { experiência } \\
\text { mínima de } 10 \\
\text { anos } \\
\text { Grupo 2: } 50 \text { não } \\
\text { músicos } \\
\text { Média de idade: } \\
31 \text { anos }\end{array}$ & Transversal & $\begin{array}{l}\text { Resolução } \\
\text { temporal }\end{array}$ & $\begin{array}{l}\text { Investigar os efei- } \\
\text { tos do contexto } \\
\text { de estímulo e da } \\
\text { experiência musi- } \\
\text { cal sobre a discri- } \\
\text { minação auditiva } \\
\text { de intervalo tem- } \\
\text { poral. }\end{array}$ & $\begin{array}{l}\text { A experiência musical, ao } \\
\text { mesmo tempo em que me- } \\
\text { lhora o desempenho, não } \\
\text { alterou o efeito de contexto, } \\
\text { sugerindo que as melhores } \\
\text { habilidades de discriminação } \\
\text { entre os músicos provavel- } \\
\text { mente não são resultado de } \\
\text { facilitação contextual mais } \\
\text { sensível ou mecanismos de } \\
\text { codificação preditiva. }\end{array}$ \\
\hline $\begin{array}{l}\text { Ouimet et } \\
\text { al. (2012) } \\
\text { Canadá }\end{array}$ & $\begin{array}{c}\text { Grupo 1: } 16 \\
\text { músicos com no } \\
\text { mínimo } 7 \text { anos de } \\
\text { experiência } \\
\text { Grupo 2: } 16 \text { não } \\
\text { músicos } \\
\text { Média de idade: } \\
20 \text { anos }\end{array}$ & Transversal & $\begin{array}{l}\text { Discriminação } \\
\text { auditiva }\end{array}$ & $\begin{array}{l}\text { Investigar o pro- } \\
\text { cessamento au- } \\
\text { ditivo global-local } \\
\text { usando material } \\
\text { melhorado base- } \\
\text { ado em estímulos } \\
\text { padrão, usados } \\
\text { em estudos sobre } \\
\text { o processamento } \\
\text { visual global-local. }\end{array}$ & $\begin{array}{l}\text { A experiência musical teve } \\
\text { efeito sobre o processamento } \\
\text { auditivo global-local, com } \\
\text { os músicos apresentando } \\
\text { melhor desempenho global } \\
\text { em comparação com os não } \\
\text { músicos. Especificamente, os } \\
\text { não músicos mostraram uma } \\
\text { vantagem global mais acentu- } \\
\text { ada em relação aos músicos, } \\
\text { impulsionada pelo fato de } \\
\text { que os músicos melhoraram o } \\
\text { processamento local em com- } \\
\text { paração com os não músicos. }\end{array}$ \\
\hline $\begin{array}{l}\text { Zarate et } \\
\text { al. (2012) } \\
\text { (19) Estados } \\
\text { Unidos da } \\
\text { América }\end{array}$ & $\begin{array}{c}\text { Grupo 1: } 13 \\
\text { músicos } \mathrm{c} / \mathrm{no} \\
\text { mínimo } 3 \text { anos de } \\
\text { experiência } \\
\text { Grupo 2: } 8 \text { não } \\
\text { músicos } \\
\text { Média de idade: } \\
\text { não informado }\end{array}$ & Transversal & $\begin{array}{l}\text { Resolução } \\
\text { temporal }\end{array}$ & $\begin{array}{l}\text { Investigar os efei- } \\
\text { tos da experiência } \\
\text { musical na discri- } \\
\text { minação de inter- } \\
\text { valos temporais. }\end{array}$ & $\begin{array}{l}\text { Embora a exposição à música } \\
\text { e à fala ocidentais possa aju- } \\
\text { dar a estabelecer um limiar } \\
\text { básico de discriminação de } \\
\text { intervalo entre } 1 \text { e } 2 \text { semitons, } \\
\text { o treinamento musical presu- } \\
\text { mivelmente melhora o proces- } \\
\text { samento auditivo e reduz esse } \\
\text { limite a um semitom. Como a } \\
\text { perícia musical não diminui } \\
\text { este limiar além de } 1 \text { semitom, } \\
\text { o semitom pode representar } \\
\text { um limite musical intervalar } \\
\text { induzido pelo treinamento } \\
\text { musical para o processamento } \\
\text { acústico. }\end{array}$ \\
\hline $\begin{array}{c}\text { Agrillo e } \\
\text { Piffer (2012) } \\
\text { (20) Itália }\end{array}$ & $\begin{array}{c}\text { Grupo 1: } 13 \\
\text { músicos c/ no } \\
\text { mínimo } 12 \text { anos } \\
\text { de experiência } \\
\text { Grupo 2: } 14 \text { não } \\
\text { músicos } \\
\text { Média de idade: } \\
28,1 \text { anos }\end{array}$ & Transversal & $\begin{array}{l}\text { Resolução } \\
\text { temporal }\end{array}$ & $\begin{array}{l}\text { Observar músicos } \\
\text { e não músicos re- } \\
\text { alizando três ta- } \\
\text { refas diferentes: } \\
\text { temporal, espacial } \\
\text { e discriminação } \\
\text { numérica. }\end{array}$ & $\begin{array}{l}\text { Como esperado, os músicos } \\
\text { foram mais precisos em rela- } \\
\text { ção à discriminação temporal. } \\
\text { Eles também deram melhores } \\
\text { desempenhos nas tarefas } \\
\text { espaciais e numéricas, mas } \\
\text { apenas fora do intervalo de } \\
\text { subitizações. Nossos dados } \\
\text { estão de acordo com a exis- } \\
\text { tência de um sistema de mag- } \\
\text { nitude comum. Sugerimos, no } \\
\text { entanto, que este mecanismo } \\
\text { não pode envolver toda a } \\
\text { gama numérica. }\end{array}$ \\
\hline $\begin{array}{l}\text { Deguchi et } \\
\text { al. }(2012)^{(21)} \\
\text { Itália }\end{array}$ & $\begin{array}{c}\text { Grupo 1: } 14 \\
\text { músicos c/ no } \\
\text { mínimo } 8 \text { anos de } \\
\text { experiência } \\
\text { Grupo 2: } 14 \text { não } \\
\text { músicos } \\
\text { Média de idade: } \\
\text { 25,9 anos }\end{array}$ & Transversal & $\begin{array}{c}\text { Ordenação } \\
\text { temporal }\end{array}$ & $\begin{array}{l}\text { Investigar as dife- } \\
\text { renças entre músi- } \\
\text { cos e não músicos } \\
\text { no processamento } \\
\text { de alterações de } \\
\text { afinação em frases } \\
\text { faladas. }\end{array}$ & $\begin{array}{l}\text { Os resultados globais confir- } \\
\text { maram a vantagem dos músi- } \\
\text { cos na detecção de mudanças } \\
\text { de tom sutis, não apenas com } \\
\text { tons, mas também com frases } \\
\text { de fala em línguas nativas e } \\
\text { desconhecidas. Esse efeito } \\
\text { parece emergir de uma análise } \\
\text { de tom mais eficiente, treina- } \\
\text { da pela experiência musical. }\end{array}$ \\
\hline
\end{tabular}




\begin{tabular}{|c|c|c|c|c|c|}
\hline $\begin{array}{l}\text { Autor(es), } \\
\text { ano e país }\end{array}$ & Amostra & $\begin{array}{l}\text { Tipo de } \\
\text { estudo }\end{array}$ & $\begin{array}{c}\text { Habilidade(s) } \\
\text { testada(s) }\end{array}$ & Objetivo & Resultados e conclusão \\
\hline $\begin{array}{c}\text { Zendel e } \\
\text { Alain (2012) } \\
\text { (22) Canadá }\end{array}$ & $\begin{array}{c}\text { Grupo 1: } 74 \\
\text { músicos com no } \\
\text { mínimo } 6 \text { anos de } \\
\text { experiência } \\
\text { Grupo 2: } 89 \text { não } \\
\text { músicos } \\
\text { Idade: entre } 18 \text { e } \\
91 \text { anos. }\end{array}$ & Coorte & $\begin{array}{l}\text { Figura fundo } \\
\text { e Resolução } \\
\text { temporal }\end{array}$ & $\begin{array}{l}\text { Investigar a pos- } \\
\text { sibilidade de que } \\
\text { os músicos expe- } \\
\text { rimentam menor } \\
\text { declínio relaciona- } \\
\text { do à idade na per- } \\
\text { cepção auditiva. }\end{array}$ & $\begin{array}{l}\text { Os músicos demonstraram } \\
\text { menor declínio relacionado à } \\
\text { idade nos testes de detecção } \\
\text { de gap e fala no ruído e reso- } \\
\text { lução temporal. É importante } \\
\text { notar que a taxa de declínio } \\
\text { relacionado à idade na sen- } \\
\text { sibilidade auditiva, medida } \\
\text { pelos limiares de tons puros, } \\
\text { foi semelhante entre os dois } \\
\text { grupos, demonstrando que os } \\
\text { músicos experimentam menor } \\
\text { declínio relacionado à idade } \\
\text { no processamento auditivo } \\
\text { central. }\end{array}$ \\
\hline
\end{tabular}

Parbery- Grupo 1: 23 Transversal Figura fundo Medir o grau em Demonstramos que os músi-

Clark et

al. (2012)

(23) Estados

Unidos da

América

músicos com no

mínimo 12 anos

de experiência

Grupo 2: 27 não músicos

Média de idade: 22,0 anos que o tempo de cos mostram maior distinção resposta subcor- neural entre sílabas de fala tical difere das sí- do que não músicos e que a labas de fala /ba/, extensão dessa diferenciação $/ \mathrm{da} / \mathrm{e} / \mathrm{ga} / \mathrm{em}$ neural se correlaciona com a músicos adultos e capacidade de perceber a fala não músicos. no ruído. Esse aprimoramento musical pode resultar de sua extensa experiência distinguindo sons estreitamente relacionados com base no timbre.

\begin{tabular}{|c|c|c|c|c|c|}
\hline $\begin{array}{l}\text { Mishra et } \\
\text { al. (2014) } \\
\text { (24) Estados } \\
\text { Unidos da } \\
\text { América }\end{array}$ & $\begin{array}{c}\text { Grupo 1: } 16 \\
\text { músicos com no } \\
\text { mínimo } 10 \text { anos } \\
\text { de experiência } \\
\text { Grupo 2: } 28 \text { não } \\
\text { músicos } \\
\text { Média de idade: } \\
25 \text { anos }\end{array}$ & Transversal & $\begin{array}{l}\text { Resolução } \\
\text { temporal }\end{array}$ & $\begin{array}{l}\text { Comparar a reso- } \\
\text { lução temporal, } \\
\text { ensaiada por li- } \\
\text { miares de detec- } \\
\text { ção de gap entre } \\
\text { canais, entre mú- } \\
\text { sicos e não músi- } \\
\text { cos carnáticos. }\end{array}$ & $\begin{array}{l}\text { Estes resultados indicam que } \\
\text { o treinamento musical tem } \\
\text { um impacto significativo nos } \\
\text { limiares de detecção de gap. } \\
\text { Especificamente, os músicos } \\
\text { têm limiares de detecção de } \\
\text { gap mais baixos comparados } \\
\text { aos não músicos. }\end{array}$ \\
\hline $\begin{array}{l}\text { Ribeiro et } \\
\text { al. }(2015)^{(25)} \\
\text { Brasil }\end{array}$ & $\begin{array}{c}\text { Grupo 1: } 15 \\
\text { músicos que } \\
\text { apenas cantam } \\
\text { sem tempo } \\
\text { mínimo de } \\
\text { experiência } \\
\text { exigido } \\
\text { Grupo 2: } 15 \\
\text { músicos que } \\
\text { cantam e } \\
\text { tocam algum } \\
\text { instrumento sem } \\
\text { tempo mínimo } \\
\text { de experiência } \\
\text { exigido } \\
\text { Média de idade: } \\
\text { 30,9 anos }\end{array}$ & Transversal & $\begin{array}{l}\text { Resolução e } \\
\text { ordenação } \\
\text { temporal }\end{array}$ & $\begin{array}{l}\text { Avaliar o proces- } \\
\text { samento temporal } \\
\text { de cantores popu- } \\
\text { lares que tocam } \\
\text { ou não instrumen- } \\
\text { to musical. }\end{array}$ & $\begin{array}{l}\text { Houve diferença estatistica- } \\
\text { mente significante na compa- } \\
\text { ração do desempenho entre } \\
\text { os grupos no que se refere ao } \\
\text { limiar de acuidade temporal } \\
\text { e percentual de acertos do } \\
\text { GIN. Cantores populares que } \\
\text { tocam instrumentos musicais } \\
\text { apresentam melhor desempe- } \\
\text { nho nas habilidades auditivas } \\
\text { de resolução e ordenação } \\
\text { temporal quando comparados } \\
\text { àqueles que só cantam. }\end{array}$ \\
\hline $\begin{array}{l}\text { Swaminathan } \\
\text { et al. (2015) } \\
\text { (26) Estados } \\
\text { Unidos da } \\
\text { América }\end{array}$ & $\begin{array}{c}\text { Grupo 1: } 12 \\
\text { músicos c/ no } \\
\text { mínimo } 10 \text { anos } \\
\text { de treinamento } \\
\text { musical } \\
\text { Grupo 2: } 12 \text { não } \\
\text { músicos } \\
\text { Média de idade: } \\
21,6 \text { anos }\end{array}$ & Transversal & Figura Fundo & $\begin{array}{l}\text { Determinar atra- } \\
\text { vés do discurso } \\
\text { inteligível e espa- } \\
\text { cial como o estí- } \\
\text { mulo-chave, se os } \\
\text { músicos mostram } \\
\text { vantagens para } \\
\text { a percepção da } \\
\text { fala em ruído em } \\
\text { situações mais } \\
\text { ecologicamente } \\
\text { válidas. }\end{array}$ & $\begin{array}{l}\text { Estes resultados sugerem que } \\
\text { as características dos masca- } \\
\text { radores de fala e a quantidade } \\
\text { de mascaramento informa- } \\
\text { cional podem influenciar a } \\
\text { magnitude das diferenças } \\
\text { encontradas entre músicos e } \\
\text { não músicos em ambientes de } \\
\text { múltiplos interlocutores. }\end{array}$ \\
\hline
\end{tabular}




\begin{tabular}{|c|c|c|c|c|c|}
\hline $\begin{array}{l}\text { Autor(es), } \\
\text { ano e país }\end{array}$ & Amostra & $\begin{array}{l}\text { Tipo de } \\
\text { estudo }\end{array}$ & $\begin{array}{c}\text { Habilidade(s) } \\
\text { testada(s) }\end{array}$ & Objetivo & Resultados e conclusão \\
\hline $\begin{array}{l}\text { Slater et } \\
\text { al. (2015) } \\
\text { (27) Estados } \\
\text { Unidos da } \\
\text { América }\end{array}$ & $\begin{array}{l}\text { Grupo 1: } 19 \\
\text { C/ } 1 \text { ano de } \\
\text { treinamento } \\
\text { musical } \\
\text { Grupo 2: } 19 \\
\text { c/ } 2 \text { anos de } \\
\text { treinamento } \\
\text { musical } \\
\text { Média de idade: } \\
8 \text { anos }\end{array}$ & Coorte & Figura Fundo & $\begin{array}{l}\text { Realizar uma in- } \\
\text { vestigação longi- } \\
\text { tudinal do efeito } \\
\text { da instrução de } \\
\text { música em grupo } \\
\text { sobre o desem- } \\
\text { penho em uma } \\
\text { medida clássica de } \\
\text { percepção de fala } \\
\text { em ruído. }\end{array}$ & $\begin{array}{l}\text { Os resultados fornecem a pri- } \\
\text { meira evidência longitudinal } \\
\text { de que a percepção de ruído } \\
\text { em ruído melhora após dois } \\
\text { anos de formação musical em } \\
\text { grupo. As crianças foram ma- } \\
\text { triculadas em um estabelecido } \\
\text { e bem sucedido programa de } \\
\text { música baseada na comunida- } \\
\text { de e seguiu o currículo padrão, } \\
\text { portanto, essas descobertas } \\
\text { fornecem um importante elo } \\
\text { entre a investigação laborato- } \\
\text { rial e avaliação do mundo real } \\
\text { do impacto do treinamento } \\
\text { de música em habilidades de } \\
\text { comunicação diária. }\end{array}$ \\
\hline $\begin{array}{l}\text { Boebinger et } \\
\text { al. (2015)(28) } \\
\text { Reino Unido }\end{array}$ & $\begin{array}{c}\text { Grupo 1: } 25 \\
\text { músicos c/ no } \\
\text { mínimo } 10 \text { anos } \\
\text { de treinamento } \\
\text { musical } \\
\text { Grupo 2: } 25 \text { não } \\
\text { músicos } \\
\text { Média de idade: } \\
27,2 \text { anos }\end{array}$ & Transversal & Figura Fundo & $\begin{array}{l}\text { Estimar se, e de } \\
\text { que maneira, os } \\
\text { músicos experien- } \\
\text { tes diferem dos } \\
\text { não músicos em } \\
\text { sua percepção da } \\
\text { fala mascarada. }\end{array}$ & $\begin{array}{l}\text { Os resultados deste experi- } \\
\text { mento demonstram a neces- } \\
\text { sidade de contabilizar habili- } \\
\text { dades cognitivas gerais antes } \\
\text { de atribuir diferenças de grupo } \\
\text { observadas ao treinamento } \\
\text { musical. Não encontramos } \\
\text { nenhuma vantagem para a } \\
\text { percepção de fala mascarada } \\
\text { dos músicos sobre a de mú- } \\
\text { sicos não músicos, e isso não } \\
\text { variou de tipo ruído. }\end{array}$ \\
\hline $\begin{array}{l}\text { Zioga et al. } \\
(2016)^{(29)} \\
\text { Reino Unido }\end{array}$ & $\begin{array}{c}\text { Grupo 1: } 22 \\
\text { músicos c/ tempo } \\
\text { de experiência } \\
\text { musical não } \\
\text { informado } \\
\text { Grupo 2: } 20 \text { não } \\
\text { músicos } \\
\text { Média de idade: } \\
\text { 23,7 anos }\end{array}$ & Transversal & $\begin{array}{l}\text { Discriminação } \\
\text { auditiva }\end{array}$ & $\begin{array}{l}\text { Investigar como a } \\
\text { música e a lingua- } \\
\text { gem interagem na } \\
\text { dimensão do tom } \\
\text { e se o treinamento } \\
\text { musical desem- } \\
\text { penha um papel } \\
\text { nessa interação. }\end{array}$ & $\begin{array}{l}\text { Os participantes foram mais } \\
\text { rápidos para violações simul- } \\
\text { tâneas da expectativa nos } \\
\text { estímulos melódicos e linguís- } \\
\text { ticos. Além disso, os músicos } \\
\text { tiveram melhor desempenho } \\
\text { do que os não músicos, o que } \\
\text { pode estar relacionado com } \\
\text { o aumento da capacidade de } \\
\text { rastreamento. O aspecto be- } \\
\text { néfico da experiência poderia } \\
\text { ser atribuído ao seu efeito de } \\
\text { fortalecimento das funções } \\
\text { executivas gerais. }\end{array}$ \\
\hline
\end{tabular}

\section{Conclusão}

Os artigos referidos no presente estudo demonstram que a prática musical influencia positivamente as habilidades do PAC. Não havendo um consenso quanto à atuação do tempo de exposição sobre essas competências, mas, evidenciando em diversos estudos, um melhor resultado de indivíduos com maior experiência musical sobre aqueles que não possuíam, ou por tempo inferior, contato prático com a música.

A revisão em questão mostrou que existe a possibilidade e a necessidade de estudos de aprofundamento, a fim de estabilizar e padronizar instrumentos avaliativos e comparativos para elucidar o envolvimento da prática musical com o aprimoramento de habilidades do PAC.

\section{Referências bibliográficas}

1. Bevilacqua MC, Martinez MAN, Balen SA, Pupo AC, Reis ACMB, Frota S. Tratado de Audiologia. São Paulo: Santos; $2011 ; 49$.

2. Freire KGM. Treinamento auditivo musical: uma proposta para idosos usuários de próteses auditivas. [Tese Doutorado em Ciências]. São Paulo: Universidade Federal de São Paulo. Programa de Pós-Graduação em Distúrbios da Comunicação Humana; 2009.

3. Torquato RJ. A alteração do processamento auditivo e a relação com a dificuldade de aprendizagem da escrita. [Monografia]. Paraná: Universidade Tuiuti do Paraná. Curso de Especialização em Psicopedagogia; 2012. 
4. American Academy of Audiology [AAA]. American Academy of Audiology Clinical Practice Guidelines: Diagnosis, Treatment and Management of Children and Adults with Central auditory Processing Disorder. 2010. Available from: http://www. audiology.org/resources/.

5. Martins JS, Pinheiro MMC, Blasi HF. A utilização de um software infantil na terapia fonoaudiológica de Distúrbio do Processamento Auditivo Central. Revi Soc Bras Fonoaudiol. 2008; 13(4): 398-404.

6. Samelli AG, Schochat E. Processamento auditivo, resolução temporal e teste de detecção de gap: revisão da literatura. Rev. CEFAC 2008; 10(3): 369-77.

7. Baran JA, Musiek FE. Avaliação comportamental do sistema nervoso auditivo central. In: MUSIEK, FE, RINTELMANN, WF (orgs.). Perspectivas atuais em avaliação auditiva. São Paulo: Manole; 2001. p.371-409.

8. Shinn JB. Temporal processing: the basics. Hear J. 2003; 56(7): 52 .

9. Machado SF. Processamento Auditivo: uma nova abordagem. São Paulo: Editora Plexus, 2003.

10. Douglas CR. Neurofisiologia da música. In: DOUGLAS, CR. Fisiologia aplicada a Fonoaudiologia. Rio de Janeiro: Editora Guanabara, 2006. p.153-60

11. Jordão G, Allucci RR, Molina S, Terahata AM. A música na escola. São Paulo: Allucci \& Associados Comunicações, 2012.

12. The Cochrane Collaboration [Internet]. Cochrane handbook for systematic reviews of interventions. 2001. [cited 2014 Aug 26]. Available from: http://www.cochrane.org/training/ cochrane-handbook.

13. Wayland R, Herrera E, Kaan E. Effects of musical experience and training on pitch contour perception. J Phon. 2010; 38(1): 654-62.

14. Nascimento FM, Monteiro RAM, Soares CD, Costa Ferreira MID. Habilidades de sequencialização temporal em músicos violinistas e não-músicos. Int Arch Otorhinolaryngol. 2010; 14(2): 217-24.

15. Monteiro RAM, Nascimento FM, Soares CD, Costa Ferreira MID. Habilidades de resolução temporal em músicos violinistas e não músicos. Int Arch Otorhinolaryngol. 2010; 14(3): 302-8.

16. Escalda J, Lemos SMA, França CC. Habilidades de processamento auditivo e consciência fonológica em crianças de cinco anos com e sem experiência musical. J Soc Bras Fonoaudiol. 2011; 23(3): 258-63.

17. Banai K, Fisher S, Ganot R. The effects of context and musical training on auditory temporal-interval discrimination. Hearing Research. 2011; 284: 59-66.
18. Ouimet T, Foster NE, Hyde KL. Auditory global-local processing: effects of attention and musical experience. J Acoust Soc Am. 2012 Oct; 132(4): 2536-44.

19. Zarate JM, Ritson CR, Poeppel D. Pitch-interval discrimination and musical expertise: is the semitone a perceptual boundary? J Acoust Soc Am. 2012 Aug; 132(2): 984-93.

20. Agrillo C, Piffer L. Musicians outperform non musicians in magnitude estimation: evidence of a common processing mechanism for time, space and numbers. Q J Exp Psychol. 2012; 65(12): 2321-32.

21. Deguchi C, et. al. Sentence pitch change detection in the native and unfamiliar language in musicians and non-musicians: behavioral, electrophysiological and psychoacoustic study. Brain Research. 2012; 1455(21): 75-89.

22. Zendel BR, Alain C. Musicians experience less age-related decline in central auditory processing. Psychol Aging. 2012 Jun; 27(2): 410-7.

23. Clark AP, Tierney A, Strait DL, Kraus N. Musicians have fine-tuned neural distinction of speech syllables. Neuroscience. 2012; 219: 111-9.

24. Mishra SK, Panda MR, Herbert C. Enhanced auditory temporal gap detection in listeners with musical training. J Acous tSoc Am. 2014; 136(2): 173-8.

25. Mondini RAC, Coelho SR, Canina PMM. Avaliação dos aspectos temporais em cantores populares. CoDAS. 2015; 27(6): 520-5.

26. Swaminathan J, Mason CR, Streeter TM, Best V, Kidd G, Patel AD. Musical training, individual differences and the cocktail party problem. Sci Rep. 2015; 5: 11628.

27. Slater J, Skoe E, Strait DL, O'Connell S, Thompson E, Kraus N. Music training improves speech-in-noise perception: Longitudinal evidence from a community-based music program. Behav Brain Res. 2015; 291(15): 244-52.

28. Boebinger D, Evans S, Rosen S, Lima CF, Manly T, Scott SK. Musicians and non-musicians are equally adept at perceiving masked speech. J Acoust Soc Am. 2015; 137(1): 378-87.

29. Zioga I, Luft CDB, Bhattachary J. Musical training shapes neural responses to melodic and prosodic expectation. Brain Research. 2016; 1650(1): 267-82.

30. Zorzal RC. Prática musical e planejamento da performance: contribuições teórico-conceituais para o desenvolvimento da autonomia do estudante de instrumento musical. Opus, [s.1], 2015; 21(3): 83-110. 